\title{
Self-translation Not Answerable to Faithfulness in Translation
}

\author{
Changyong Zou \\ Zhujiang College of South China University \\ Guangzhou, China
}

\begin{abstract}
To be absolutely faithful in translation has long been the ultimate goal for many translators. Due to semantic, stylistic and cultural reasons, it seems an impossible mission. Some suggest that self-translation may be the only possible answer toward faithfulness in translation. With the writer and translator being the same person, there aren't any problems in understanding the original text and the writer-cum-translators can best adhere to it both in language and in style. By investigating into such famous self-translators as Xiao Qian, Lin Yutang, Zhang ailing, Bai Xianyong, etc, we find that even self-translators can not guarantee the complete equivalence in translation due to the following reasons: (1). translators' subjectivity; (2). translators' pursuit for perfection; (3). adaptation to the target readers; (4). cultural factors outside translation.
\end{abstract}

Keywords—self-translation; variation; faithfulness

\section{INTRODUCTION}

People have carried out self-translations for many years and quite a lot famous writers have turned their works into another language. For instance, Tagore's self-translation of Gitajiali has earned him international fame as one of most prestigious poets. Many famous writers in China have also translated their own writing into English. Writers like Lin Yutang, Zhang Ailing, Xiao Qian, Xu Dishan, and Zheng Zhenduo have turned many of their works into English and made great achievements.

There are different definitions with regard to what is selftranslation. According to Rainier Grutman, "the term "selftranslation" can refer both to the act of translating one's own writings into another language and the result of such undertaking". (Rainier Grutman; 257). Anton Popovic defines self-translation as "the translation of one's own works into another language by the author himself". (Shuttleworth \& Connie, 13). As both two definitions of selftranslation refer to "one's own writings" or "one's own works", the materials collected in this paper will be limited to literary self-translation only.

In literary translation, to be completely faithful in language and style remains virtually impossible. Hard as many translators try, gaps between cultures and losses in meaning have often occurred in translation. It is believed that at least two causes account for the unfaithfulness: (1). translators' deviation in translation; (2). multiplicity of meaning in the original text. No matter how responsible a translator may be, when translating, he is apt to mingle his own intentions with the writer's. At this time, his own experience, his language ability, and his cultural background will take effect and cause divergence in translation. Also, a certain word in original text may have different meanings. The translator's choice of word may vary with different interpretations.

It seems the deviation in translation solvable only in one way - self-translation. Should the translator and writer be the same person, it is naturally assumed that he knows his own purpose in writing and he can best follow his own style in translation. Thus, if he translates his own works, he can achieve complete "linguistic and stylistic equivalence" and the issue of not being faithful is naturally eliminated. Is it really the case? This paper, by investigating into the selftranslated works of several writer-cum-translators, finds that self-translation does not guarantee complete faithfulness in the traditional sense. Out of some particular needs, the translators deliberately change the style or contents in their translations.

\section{CHARACTERISTICS OF SELF-TRANSLATION}

\section{A. Certainty in Decoding the Original Text}

Translation involves the decoding of the source language and encoding of the target language. Therefore, translation by nature calls for fidelity or faithfulness. However, translators may encounter quite a lot ambiguity in translation as is mentioned above. When they are uncertain about some words, their choice of words may vary with their own experience and understanding, which may be different from the writers'. Thus, the translator has to be very careful lest being unfaithful to the original text. The self-translators do not have to worry about this. They seem to enjoy "superiority in manipulation" (Chen Yihai, 17). As the writers themselves, they are endowed with certain privilege and right in interpreting the theme, emotions and some certain ambiguous words. Therefore, they are supposed to be fittest to translate their own works as they enjoy certainty in decoding the original text.

\section{B. More Subjectivity in Translation}

We have discussed above that self-translators have privilege in understanding and decoding the original text. Yet we find even self-translators are unable to achieve 
linguistic and stylistic equivalence in translation. Compared with other translators, who usually follow writers like shadows, self-translated works are more arbitrary, changeable, and free. Many famous writer-cum-translators have applied different methods when translating their own works and others'. For example, Xiao Qian, when translating Ulysses, applies a full-translation plus notes method, while there are quite a lot deletion, addition, variation, etc, in his self-translated works. The same is true with Bian Zhilin's self-translation of his poems. "His translation from English to Chinese follows a literal translation method with much restraint, thoroughness and fidelity, sometimes to the extent that his being a shadow of the original works, while in the translation of his own poems he applies a more literary technique, being more arbitrary, variable and even free at will” (Bei Ta, 26).

Translating their own works grants self-translators more right and freedom in the dispose of the original text. They inevitably demonstrate more subjectivity in their selftranslation. In the translation of The Death of An Air-Ace, Xiao Qian add lengthy background information and commentary remarks about Liu Cuigang's death. This is quite unusual in the traditional sense of translation and would be considered as unfaithful if the addition had been done by other translators.

\section{Variations in Self-translation}

Though self-translation is supposed to be most faithful, it turns out to be the contrary. Compared with other translators, writer-cum-translators often put their creative genius into translation as well. They often add, delete, adapt when translating. Wu Bo, by investigating Bai Xianyong's self translation of Taibei People, finds that even translator and writer being the same person does not guarantee complete faithfulness. Bai deliberately make adjustments in the content or change the style out of some particular needs. According to $\mathrm{Wu}$, "the self-translator Bai Xianyong assumes a much more profound and complex role than just being faithful to the writer and the original work". (Wu Bo; 68). Professor Lin Kenan studies Xiao Qian's self-translation and finds that Xiao does not follow the traditional method of literal translation, but adopt a more adventurous way of using addition, deletion and variation. In Xiao Qian's translation of his own novel Epidemic, he deliberately deletes lengthy description of the maltreatment a servant received from his master. In Zhang Ailing's self-translation, she has adopted such techniques as deletion, addition and narrative changes. Zhang appeals to her target readers by displaying them a much barbarian civilization in which Chinese are described as backward, barbarous, corrupted and autocratic, while the westerners are civilized, free and advanced. In her translation, the detailed description of furniture, clothes, and hair style, which signal her status as feminist writer, are deleted in her self-translation. Lin Yutang's self-translation of Between Tears and Laughter also displays his literary genius and his in depth understanding of the original text. When his own translation is compared with those of others, his seemingly unfaithful and rebellious version, when studied carefully, often turn out to be the best, grasping the essence of the original text.

\section{UNDERLYING CAUSES FOR THE UNFAITHFULNESS IN SELF-TRANSLATION}

Compared with translation by others, self-translation does possess its own peculiarities which differentiate it from usual translation practice. Unfaithfulness, even variations widely exist in self-translation. The following causes may account for them.

\section{A. The Translator's Subjectivity}

With their own copyright, self-translators demonstrate more subjectivity in translation. Out of certain needs and necessities, they tend to employ more techniques in their translation. In the process, self-translators exam the original text critically and adopt different methods and techniques, continuously interacting with target readers and source text. They will "inevitably penetrate their individual style, aesthetic sentiment and standard of value, and present their own understanding of the meaning by means such as active reading, constructing, paraphrasing and interpreting. This trend gives translators more room to bring their talents into full display". (Kuang Yan; 26-27).

In Lin Yutang's self-translation of Between Tears and Laughter, he displays his master skill of Chinese language and artistic beauty far beyond any other ordinary translators do. He seems to "lay more emphasis on faithfulness on the whole rather than partial fidelity" (Li Ping, Cheng Le; 89). It is the gist, not the language that Lin intends to convey to another audience. Lin's own translation has the touch of time and proficiency and craftiness unimagined by other translators. Therefore, self-translation, in essence, is a reexperience, rethinking, and re-expression of the writers on the basis of his original work. They will inevitably demonstrate their own individuality and ideology, which are reflection of his subjectivity as translators.

\section{B. Adaptation to the Target Readers}

In the early days, translators are often depicted as "tongue man" or "invisible man" or even "slave". Their statuses are seemingly inferior to the writers as the above terms display. Cases are different with self-translators. Being the writers themselves, they are apt to be more "readercentered" than "writer-centered" so as to introduce their works to a wider audience. In the process, they may even adopt certain skills and techniques in translation to curry favor with the target readers. Wang Xiaoying takes a postcolonial perspective and finds that Zhang Ailing has shown a strong inclination to please American readers in her selftranslation. In her book Naked Earth, a few words describing an ordinary scene in which inland country fellows gather to see and point to a truck in 1950 s has been translated into more than 200 English words. Zhang add such words as "odd, savage, greasy" (Wang Xiaoying; 128) to describe the inland farmers. These added words in her self-translation cater to the imagination of westerners about China and its people. Zhang, by portraying the ridiculous, barbarous, and 
backward Chinese, shows to the American readers an inferior culture and offers them an exotic taste.

Self-translators' adaptation is also manifested in their consideration for the target readers. Lin Yutang, when translating Between Tears and Laughter, uses the most fluent and authentic Chinese language. The natural flow of words and artistic sentiment revealed make his readers unaware of the fact that it is translation. Bian Zhilin, in his translation of his own poems, clarifies some of the images and meanings, making them actually easier for the readers to understand.

\section{Writers' Pursuit for Perfection in Self-translation}

Hard as a writer may have tried in his writing, there are always some defects which are not to his satisfaction. Even if he is utterly content with his own works, his cognition, thoughts and artistic sentiment may vary with time, experience, etc. In this case, self-translation gives the writer another chance to rewrite the text and make improvement. Xiao Qian, when translating his own work Scenery from Yentang Mountain, has condensed the original text of 25, 000 words to a translation of only 1, 800 words. Even though Xiao does not make any specific explanation as to why he has made such arrangement, it can be assumed that he may feel lengthy about the original text and wants to make some improvement in translation.

Sometimes writers may pursue artistic perfection. If it can not be realized in writing, he will continue his pursuit in translation. Lin Yutang wrote Between Tears and Laughter in his prime time as a writer. This book was about "the writer's recipe toward the root of political riot and ethical perishment after the world war" (Chen Huiquan; 169). In its translation, Lin puts to use an elegant style and very refined words. With its style and language much assemble the literature classics of ancient china; Lin Yutang exhibits his "wild ambition" to be on the par with the Chinese literature immortals. With a natural flow of artistic fluidity and language attainment, "Lin's Chinese version surpasses its English original. It's hard for us to distinguish between the original and its translation." (Feng Xinxin; 27-28)

\section{Cultural Factors Outside Translation}

Cultural school of translation believes that translations are influenced by cultural factors as dominant poetics, ideology and patronage. Lefevere, one of the representatives of cultural school, regards translation as a sort of rewriting. He claims that "if linguistic considerations enter into conflict with considerations of an ideological and/or poetological nature, the latter tend to win out". (Lefevere; 1992a:39). This can explain several massive translation activities in china history. In late Qing dynasty, quite a lot of western books were introduced to China, not out of linguistic necessity, but because of ideological needs. The progressive thinkers intend to enlighten China with translation of famous books. The same is true with the translation of the literary works of the Soviet Union. These translations serve for politic purposes and attest the validity of cultural effects.

Self-translators are also influenced by these factors outside translation. Zhang Ailing was financially aided by the American News Agency and wrote Naked Earth according to the compendium offered to her. In 1955, its translation was published by Union Press, which was associated with American News Agency. With "the foreigners in Asia as its target readers", this translation by Zhang Ailing herself fulfills the purpose of meeting westerners' expectancy of China. In Naked Earth, Chinese people are generally depicted as derogatory. Zhang's efforts in self-translation seem to cater to the ideology of American peole, especially those who are Anti-China. (Wang Xiaoying; 128).

\section{CONCLUSION}

By investigating into the Chinese-English self-translation of many famous writers, this thesis concentrates on the connection between self-translation and faithfulness. It is found that self-translation does not ensure faithfulness. Instead, self-translators dispose their original text in a more free, arbitrary manner and causes adjustment or even variations in their translation. These variations can not be explained by traditional translation theories regarding the "faithfulness" or "equivalence". Therefore, it is proposed that the writers' subjectivity, their pursuit for perfection, adaptation to their readers and cultural factors outside translation may account for these variations. Finally, we can draw the conclusion: self-translation is not answerable to faithfulness in translation.

\section{REFERENCES}

[1] Mona Baker \& Gabriela Saldanha. Routledge Encyclopedia of Translation Studies. Shanghai Foreign Education Express. 2010.

[2] Jeremy Munday. Introducing Translation Studies. Shanghai Foreign Education Express. 2010.

[3] Andrew Lefevere. Translation, Rewriting And The Manipulation Of Literary Fame. Shanghai Foreign Education Express. 2010.

[4] Andrew Lefevere. Translation/History/Culture A Source Book. Shanghai Foreign Education Express. 2010.

[5] Chen Yihai, When a Poet Is a Translator-A Tentative Study of Poets' Self-translation, China Comparative Literature. vol 3, pp. 17, 2013.

[6] Lin Kenan, Toward Methodological Diversity in Literary Translation: Xiao Qian as an Exemplar, Chinese Translators Journal, vol 3, pp. 44-47, 2005

[7] Bei Ta, Bian Zhilin's Self-Translation of His Poems, Journal of Southwest China Normal University (Humanities and Social Science Edition), vol 5, pp. 24-28, 2006.

[8] Wu Bo, On the Task of the Translator-A Case Study on the SelfTranslation of Taibei People, Shandong Foreign Language Teaching Journal, vol. 103, pp. 65-68, 2004.

[9] Wang Xiaoying, Eileen Chang's Chinese-English Self-Translation: A Post-colonial Perspective, Foreign Language and Literature, vol. 25, pp. 125-129, 2009.

[10] Kuang Yan, A Study of Translation Variation in Xiao Qian's SelfTranslated Works: From the Perspective of Translator's Subjectivity, Central South University, pp. 26-27, 2007.

[11] Li Ping, Cheng Le, Fidelity Revisited: A Case Study of Lin Yutang's Self-Translation, Journal of Zhejiang Gongshang University, vol 116, pp. 89, 2012.

[12] Chen Huiquan, Literary Self-Translation: A Case Study of Lin Yutang's Between Tears and Laughter, Zhejiang University of Finance and Economics, pp. 169, 2009. 
[13] Feng Xinxin, On the Translation of Between Tears and Laughter-A Comparative Study of Lin Yutang's and Song Biyun's Translation, Anhui Literature, vol. 1, pp. 27-28, 2013. 